\title{
The use of rotation to fentanyl in cancer-related pain
}

\author{
Delia Dima' \\ Ciprian Tomuleasa' \\ loana Frinc' \\ Sergiu Pasca ${ }^{2}$ \\ Lorand Magdo 2 \\ loana Berindan-Neagoe ${ }^{2-4}$ \\ Mihai Muresan ${ }^{5}$ \\ Cosmin Lisencu ${ }^{5}$ \\ Alexandru Irimie 5 \\ Mihnea Zdrenghea ${ }^{1,7}$ \\ 'Department of Hematology, lon \\ Chiricuta Oncology Institute, ${ }^{2}$ Faculty \\ of Medicine, Research Center for \\ Functional Genomics and Translational \\ Medicine, Iuliu Hatieganu University \\ of Medicine and Pharmacy, luliu \\ Hatieganu, ${ }^{3}$ Department of Functional \\ Genomics, The Oncology Institute \\ Ion Chiricuta, ${ }^{4}$ Medfuture Research \\ Center for Advanced Medicine, \\ University of Medicine and Pharmacy, \\ luliu Hatieganu, ${ }^{5}$ Department of \\ Surgery, Ion Chiricuta Oncology \\ Institute, ${ }^{6}$ Department of Oncology, \\ University of Medicine and Pharmacy, \\ luliu Hatieganu, ${ }^{7}$ Department \\ of Hematology, luliu Hatieganu \\ University of Medicine and Pharmacy, \\ Cluj Napoca, Romania
}

Correspondence: Ciprian Tomuleasa Department of Hematology, Ion Chiricuta Oncology Institute/Research Center for Functional Genomics and Translational Medicine, luliu Hatieganu University of Medicine and Pharmacy, Strada Gheorghe Marinescu No 23, Cluj Napoca 400124, Romania Tel +40 $26474 I 337480$ Email ciprian.tomuleasa@umfcluj.ro
This article was published in the following Dove Press journal:

Journal of Pain Research

9 February 2017

Number of times this article has been viewed

\begin{abstract}
Pain is commonly diagnosed with respect to cancer and heart diseases, being a major symptom in most neoplastic diseases. Uncontrolled pain leads to a decrease in the quality of life and an increase in the morbidity of the patient. Opioids represent the best analgetic supportive therapy and are frequently used in patients suffering from cancer and experiencing a high level of pain. Opioid treatment starts with a gradual titration of the dose until the minimum effective dose and the maximum tolerated dose are determined. Opioid rotation refers to the switch from one opioid to another in order to get a better response to analgetic therapy and reduce side effects. Fentanyl therapy is recommended to be continued during chemotherapy, radiotherapy, or in the case of surgical intervention. Rotation to fentanyl patches is an efficient and elegant solution for cancer patients, with reduced side effects. Opioid rotation, especially to fentanyl, was shown to increase the quality of life in patients with malignant disease. Finally, rotation to fentanyl is also advantageous from an economic point of view.
\end{abstract}

Keywords: opioid rotation, cancer-related pain, fentanyl

\section{Introduction}

Prevalence of pain is a predominant factor in cancer and heart diseases, ${ }^{1}$ and pain is a major symptom in most neoplastic diseases. Uncontrolled pain leads to a decrease in the patient's quality of life and an increase in morbidity. To preserve the quality of life, chronic pain must be treated continuously and as noninvasively as possible., ${ }^{2,3}$ Pain management is frequently complicated by under-reporting of pain by patients (eg, because of fear of addiction) or because its priority is minimalized by health care professionals. ${ }^{4,5}$ Before initiating analgetic therapy, a thorough anamnesis of the pain symptoms is required including the type of pain, duration, intensity, localization, factors that aggravate or alleviate the pain, anterior and associated medication, and any previous alcohol or drug abuse. Treatment compliance should also be taken into consideration. The patient must understand and agree to the importance of the treatment and must respect its correct schedule, even as symptoms improve. Any changes in the treatment course could lead to exacerbations, which can elicit doubts from the patient regarding treatment efficacy. All these may lead to an unnecessary increase of the medication dose and, subsequently, of its side effects. It can also trigger treatment changes, leading to a difficult-to-control vicious cycle. ${ }^{6}$

Opioids represent the best analgetic supportive therapy and are frequently used in cancer patients experiencing high levels of pain. Opioid treatment starts with a gradual dose titration in order to establish the minimum effective dose and the maximum tolerated dose. ${ }^{7,8}$ A proper risk evaluation must be undertaken when prescribing opioids, 
taking into account the over-reporting of symptoms and the prospective of opioid abuse. A drug abuse history and/or previous sedative use should be investigated. ${ }^{1}$

Opioid rotation is the term used to describe the switch between different opioids, usually from a short-acting to a long-acting preparation, in order to improve both patient adherence and pain control. ${ }^{9-11}$ It also refers to changing opioid treatment to obtain a better side effect profile. Finally, rotation can restore the decrease in opioid analgetic efficiency. ${ }^{12}$ This approach has been used for over 20 years and is regarded as the standard-of-care in the field. ${ }^{13}$ According to Mercadante et al, ${ }^{13}$ the new opioid is administered at a safe dose, which maintains the balance between analgetic and adverse side effects. The new drug also needs to have at least the same level of analgesia as the previous one. Furthermore, opioid rotation involves a switch from a drug that has short-term effects (and is usually employed to initiate the course of treatment) to a drug with long-term effects. ${ }^{14}$ The motives behind opioid rotation are insufficient analgesia (especially for outpatients), adverse effects (especially in the case of inpatients with neurological side effects), drug interactions, risk of addiction, or accessibility problems. ${ }^{13}$ Around $21 \%-44 \%$ of patients treated with opioids will require a change in their treatment course at some point during the evolution of their disease. ${ }^{15}$ In the opioid rotation algorithm, it is important to know that morphine is the "standard" opioid, starting from 1 dose every 24 hours. ${ }^{16}$ Therapeutic success is considered when a decrease by at least $33 \%$ of the pain level and/or of the distress score is obtained. ${ }^{13}$

The action and potency of opioids depend on multiple variables. ${ }^{1}$ Differences in treatment responses can be explained by different medication pharmacokinetics and metabolic factors that include CYP450 and UDP-glucuronosyltransferase enzyme, receptor binding, phosphorylation of the receptors, as well as patients' characteristics, such as age, ethnicity, comorbidities, genetics, and associated medication. ${ }^{1,13}$ Differences between opioid receptors and their affinity for the various opioids have been reported, as well as different polymorphisms that alter the amino acid sequence and thus lead to modification of the receptor function. ${ }^{13}$ Hayashi et al have shown that albumin levels affect fentanyl biodisponibility ${ }^{17}$ and, therefore, for patients with albumin serum levels under $3 \mathrm{~g} / \mathrm{dL}$, the transition from morphine or oxycodone to fentanyl may be inefficient. ${ }^{18}$ Didwaniya et al underline that for patients suffering from bowel obstructions, the administration of fentanyl is preferred to orally administered opioids. ${ }^{19}$ White blood cell count, the patient's weight, concomitantly administered beta blockers, 5HT3 anti-emetics, proton pump inhibitors, the presence of a lower gastrointestinal tract neoplasm, and recent chemotherapy are among the important factors that determine the choice/ change of the opioids. ${ }^{20}$ Thus, the opioid treatment should be highly personalized. ${ }^{13}$

Increased access to a wider choice of opioids in the past has led to a consecutive increase in opioid rotation. ${ }^{21}$ Multiple studies have shown that opioid rotation causes symptomatic relief and a drop in the intensity of side effects in 50\%-90\% of cases.

Fentanyl is a semi-synthetic, liposoluble, pure opioid agonist, with inactive metabolites, and is available as a transdermal patch. Fentanyl is 80 times more potent than morphine, with effects observable at 6-8 hours after applying the patch, and a stable status being obtained after 72 hours; it has a half-life of 16 hours. ${ }^{22}$ The drug is absorbed due to the concentration gradient between the patch and the skin. After being absorbed into the bloodstream, it is distributed around the entire body and interacts with the opioid mu-receptors, mostly located in the central nervous system (Figure 1). ${ }^{23}$

Although fentanyl is efficient in pain management, the data on its use in oncologic pain management and the possibility of switching to another opioid are limited. However, the European Association for Palliative Care recommends fentanyl as an efficient alternative to oral morphine, especially for patients with a constant need for opioids. One of the substantial advantages of fentanyl is the easy route of administration. ${ }^{24}$ In addition, studies show that fentanyl is associated with a lower incidence of constipation as a side effect. ${ }^{25}$ An important aspect of rotation from morphine to fentanyl is the intrinsic activity of the latter, which determines its efficiency and is inversely proportional to the level of drug-receptor binding, as shown in Figure 2. ${ }^{26}$

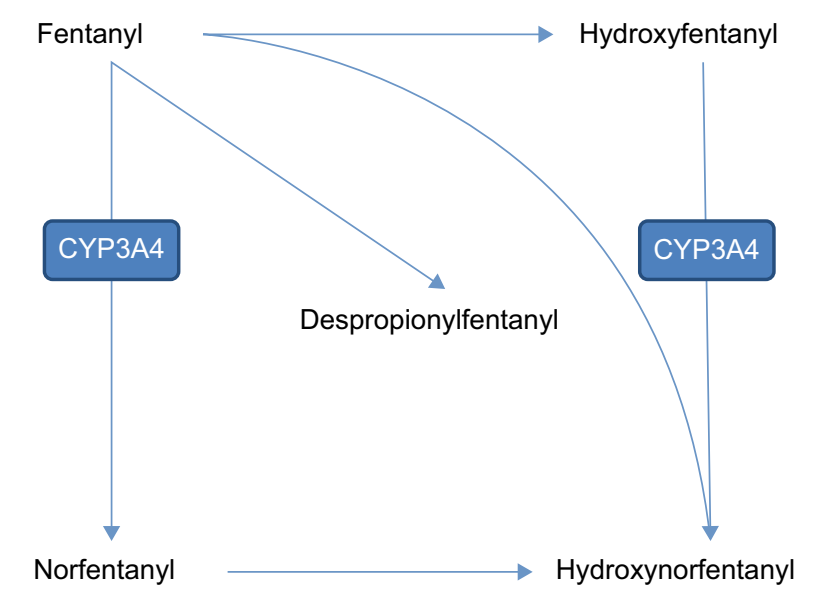

Figure I Fentanyl metabolism. 


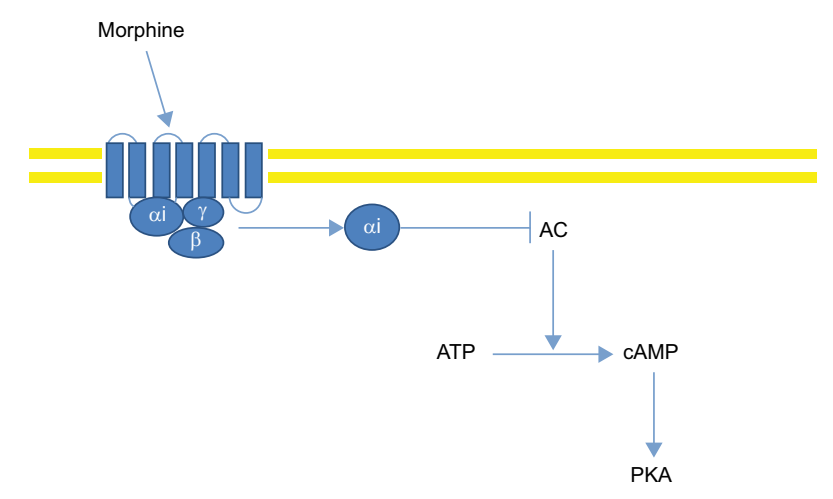

Figure 2 Morphine acts on its transmembrane receptor.

Note: When activated, this receptor stimulates a $\mathrm{Gi}$ protein to separate into the alpha inhibitor subunit and the beta-gamma subunit. The alpha inhibitor subunit inhibits adenylate cyclase, which - as a result - does not produce cAMP, an activator of protein kinase $A$

Abbreviations: ATP, adenosine 5'-triphosphat; cAMP, cyclic adenosine 5'-monophosphat; PKA, protein kinase.

It is known that morphine has a high level of receptor occupation, which leads to a decrease in drug efficiency with increasing dosages. On the other hand, fentanyl has been proven to be effective for equinalgesic doses in morphinetolerant mice. $^{27}$

\section{Purpose of the study}

There are no randomized studies regarding opioid rotation and most current recommendations are based on retrospective or observational studies. ${ }^{15}$ Furthermore, the dose conversion is not just simple mathematic numeracy as the type and intensity of the pain, the current complaint, the comorbidities, and the associated medication must all be taken into account. ${ }^{28}$ Although there are comparative studies between fentanyl and morphine, the conversion rate between the two drugs remains unclear.

\section{Literature search}

The studies included in the present analysis were identified after a search of the National Library of Medicine's MEDLINE database using PubMed and Google Scholar. Candidate papers were limited to English, German, and French language publications, but were not limited to any geographical region, and the most recent search was performed on July 28, 2016. Only papers published between 1977 and 2015 were considered in order to avoid any inconsistencies in diagnostic criteria and also cover the period of publications on opioid rotation. The search strategy was based on the combination of the keywords “opioids", “opioid rotation", "cancer", "fentanyl”, and "pain management". Subsequently, an additional manual search of the citations of the previously selected papers was performed.

We found 179 articles, of which we excluded three papers related to pediatric oncology and three papers related to nononcologic chronic pain. We also considered the NCCN and American Pain Society guidelines. ${ }^{29}$

\section{Results}

During our first search, we found 52 reviews and 69 clinical trials. Of these, 13 investigated the rotation from oral or parenteral opioids to fentanyl patches and two studied the rotation from fentanyl to other opioids, as shown in Figure 3 and Table $1 .^{30}$

\section{Discussion}

Opioid rotation is achievable in an outpatient setting. In a study conducted by Reddy in $2013,{ }^{31} 65 \%$ of the patients treated as outpatients achieved analgesia after opioid rotation for uncontrolled pain. ${ }^{32,33}$ These results are far superior to those shown by McNicol in 2003. ${ }^{34}$ The ROTODOL multicenter prospective study, which included 67 patients with cancer, demonstrated that opioid rotation is efficient and safe. ${ }^{35}$

The studies presented in Table 1 show that the fentanyl patch is efficient in the case of rotation from morphine with prolonged release and has fewer adverse effects. In 2012, Ikeda demonstrated that fentanyl is efficient and less toxic compared with fast release morphine and oxycodone. The evaluated patients, treated with fentanyl patches, reported significantly less constipation, nausea, vomiting, and dizziness. ${ }^{36}$

Between 2010 and 2013, Reddy et al retrospectively evaluated 6,790 oncology patients, of whom $88 \%$ had been receiving opioid treatment, and in $35 \%$ of patients rotation to fentanyl was performed, in $80 \%$ of cases for uncontrollable pain. The morphine to fentanyl dose conversion was 100:1 (mg) and 2.5:1 $(\mu \mathrm{g} / \mathrm{h}){ }^{37}$ Therapeutic success was considered with a $30 \%$ reduction in the degree of pain or a

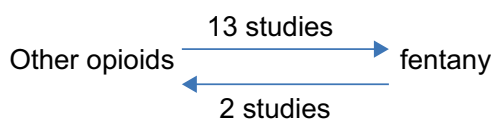

Reviews $\quad$ Clinical trials

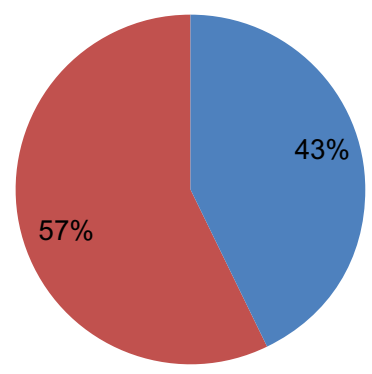

Figure 3 Distribution of papers included in our study. 
Table I Studies included in this article

\begin{tabular}{|c|c|c|c|c|c|}
\hline Study name & Study type & $\begin{array}{l}\text { Rotation to fentanyl } \\
\text { motive }\end{array}$ & $\begin{array}{l}\text { Number of } \\
\text { patients }\end{array}$ & Conversion rate & Results \\
\hline Mercadante ${ }^{9}$ & Prospective & Uncontrolled pain & 321 & $100: 1$ & Pain relief in $3-7$ days \\
\hline Reddy et $\mathrm{a}^{31,37}$ & Retrospective & Uncontrolled pain & 6,790 & $100: 1$ & Pain relief \\
\hline Ikeda et a ${ }^{36}$ & Prospective & Adverse effects & 9 & & $\begin{array}{l}\text { Pain control in } 4 \text { weeks, } \\
\text { pain relief and side } \\
\text { effects }\end{array}$ \\
\hline Kawano et $\mathrm{al}^{21}$ & Prospective & $\begin{array}{l}\text { Modification of } \\
\text { administration route }\end{array}$ & 57 & $50: 1$ & Controlled pain \\
\hline Hanaoka et al ${ }^{50}$ & Prospective & Pharmacology & 66 & & Controlled pain \\
\hline Akiyama et $\mathrm{al}^{4 \mathrm{I}}$ & Retrospective & $\begin{array}{l}\text { Adverse effects, route of } \\
\text { administration }\end{array}$ & 24 & $96,6: 1$ & $\begin{array}{l}\text { Controlled pain and less } \\
\text { adverse effect }\end{array}$ \\
\hline Ripamonti et a ${ }^{42}$ & Prospective & Comparison & 98 & $100: 1$ & $\begin{array}{l}\text { Good efficiency of } \\
\text { fentanyl }\end{array}$ \\
\hline Freynhage et a ${ }^{48}$ & Prospective, multicenter & Route of administration & 46 & Equivalency & $\begin{array}{l}\text { 91 patients preferred } \\
\text { matrix patches }\end{array}$ \\
\hline Morita et al ${ }^{53}$ & Prospective & Delirium & 20 & $200: 1$ & $\begin{array}{l}\text { Pain and delirium } \\
\text { amelioration in } 3 \text { days }\end{array}$ \\
\hline Kato et a $\left.\right|^{38}$ & Prospective & Adverse effects & 144 & $78: 1$ & $\begin{array}{l}\text { Efficiency, adverse } \\
\text { effects relieve }\end{array}$ \\
\hline Radbruch and Elsner ${ }^{46}$ & Prospective & Insufficient analgesia & 996 & $100: 1$ & $\begin{array}{l}\text { Efficient, reduced } \\
\text { adverse effects }\end{array}$ \\
\hline Mystakidou et $\mathrm{a}^{43}$ & Prospective & Uncontrolled pain & 130 & & Controlled pain \\
\hline Elsner et $\mathrm{al}^{\mid 47}$ & Retrospective & Adverse effects & 64 & $70-100: 1$ & $\begin{array}{l}\text { Controlled pain and less } \\
\text { adverse effects }\end{array}$ \\
\hline
\end{tabular}

decrease by two points of the Edmonton System Assessment System (ESAS) score. The results of the study showed a significant improvement of analgesia, insomnia, anxiety, and digestive disorders, such as nausea and/or constipation. The study failed to identify individual predictive factors for the efficiency of rotation; the factors under investigation were gender, age, type and stage of the cancer, the presence of mucositis ( $50 \%$ of the patients presented mucositis), history of drug abuse or tobacco, body surface or the serum albumin level, ESAS score, pain characteristics or CAGE (cut-down, annoyed, guilty, and eye-opener) score.

Kato et al calculated the conversion dose of oral morphine to fentanyl patch and obtained a ratio of 78:1. A similar result was obtained by Donner et al who showed an equianalgesic conversion of 70:1 between oral morphine and fentanyl. The conclusions of these two studies are interesting and important, when considering the conversion ratio of 150:1 indicated on the fentanyl package insert. ${ }^{38-40}$

In 2007, 22 cancer patients were treated with fentanyl patches, with rotation being performed, for administrative reasons, at discharge. In the study of Akiyama et al, only four patients did not tolerate the treatment due to adverse effects (diarrhea) or because of treatment inefficiency. ${ }^{41}$ Subsequently, Ripamonti et al evaluated the use of transdermic fentanyl in 98 patients with malignant disease. The main reason for rotation to fentanyl was analgesia failure (in $57.1 \%$ of patients treated as outpatients and $62.9 \%$ for hospitalized patients). Other reasons included dysphagia, nausea/vomiting, or severe constipation. Initial medication consisted of nonsteroidal anti-inflammatory drugs, tramadol and oral morphine. The mean ratio of conversion was 71:1. The authors emphasized the need for a slow titration process, which could take 17-48 hours, and some patients only experienced analgesia when employing the second patch. This, however, could generate a high risk of adverse effects because of an unjustified increase of the dose. ${ }^{42}$

This same trend was observed by Mystakidou et $\mathrm{al}^{43}$ in 130 oncology patients treated with codeine in which rotation to fentanyl was performed for insufficient analgesia. ${ }^{39,44}$ In these patients, the fentanyl dose was increased during the first 3 days, with only $39 \%$ of the patients staying on the initial dose of $25 \mu \mathrm{g} / \mathrm{h}$. Another study conducted by van Seventer et al showed that fentanyl is as effective as extended release morphine in opioid-naïve patients, but during the first week of treatment the patients needed more rescue medication. ${ }^{43,45}$

Radbruch et al highlighted the efficiency of fentanyl patches in 996 cancer patients who were opioid resistant or naïve. The treatment was well tolerated with $75 \%$ of the patients reporting a net improvement of painful symptoms. 
The maximum dose was $21.6 \mathrm{mg}$ of fentanyl (nine patches of $100 \mu \mathrm{g})$. Regarding adverse effects, $6 \%$ of the patients presented nausea, 3\% vomiting, and 4\% presented constipation. Neurologic adverse effects were rare: $0.1 \%$ experienced convulsions and $0.2 \%$ hallucinations; $35 \%$ of patients stopped fentanyl therapy, of which $10 \%$ was due to analgesia failure. Respiratory distress was reported in only eight patients, without a clear causal relationship. There were $12 \%$ of patients who reported dermatological side effects, but only three patients discontinued the treatment. During the study period, 72 major surgical interventions were performed on the patient group, and only 18 patients interrupted the treatment for the intervention. The majority of patients continued the treatment until death. Although the price of fentanyl exceeds the price of oral morphine, the cost/efficiency ratio was favorable. ${ }^{46}$

Elsner et al investigated the efficiency of fentanyl in 101 patients. These patients were switched to fentanyl for insufficient analgesia under treatment with extended release morphine $(48 \%)$, immediate release morphine (17\%), buprenorphine (11\%), tramadol (11\%), levomethadone $(5 \%)$, tilidine/naloxone $(5 \%)$, or piritramide $(3 \%)$. Reasons for rotation included analgesia failure in $33 \%$ of patients; the need to reduce oral medication in $20 \%$ of patients; $31 \%$ for nausea; $13 \%$ for vomiting; $19 \%$ for constipation and $27 \%$ for dysphagia. The investigators used a morphine:fentanyl conversion ratio of 100:1, but propose a $70: 1$ ratio. $^{47}$

Furthermore, Freynhagen et al demonstrated the efficiency of a matrix form of fentanyl. Classically, fentanyl is found in the form of a patch that contains a reservoir of fentanyl and betanol, a control membrane for fentanyl release, and a silicon-based adhesive (Figure 4). A total of 46 patients were treated with the new matrix-form fentanyl, which does not contain the medicine reservoir or the control membrane, but only fentanyl dissolved in a polyacrylate film. The majority of patients reported proper analgesia comparable with the reser- voir fentanyl. The degree of satisfaction, ease of use, comfort, and compatibility with the skin, make the fentanyl matrix a suitable form for rotation instead of the reservoir fentanyl. ${ }^{48}$

Very few studies have been published to date on the conversion between parenteral morphine and fentanyl. The rate of conversion used in clinical practice of 50:1 is obtained from the conversion of 150:1 oral morphine:fentanyl and 3:1 oral morphine:injectable morphine, as seen in Tables 2 and 3. Change in the treatment schedule from injectable morphine to another opioid is important in current practice, especially at discharge and for home treatment, in situations in which an intravenous or subcutaneous route is not available, in cases of reduced compliance, difficult access to continuous infusion pumps, etc. ${ }^{49}$ Kawano et al included 57 patients with solid cancers in their study and supported the feasibility of rotation from continuous morphine to fentanyl patches, with a conversion ratio of 50:1, but also showed that fentanyl doses increased with the equivalent target morphine dose, ${ }^{21}$ as seen in Table 4.

Table 2 The rate of conversion between opioids

\begin{tabular}{ll}
\hline & Time to conversion \\
\hline Oral methadone & $5-10$ \\
Transdermal fentanyl & 100 \\
Transdermal buprenorphine & 70 \\
Oral hydromorphone & 5 \\
Oral oxycodone & 1.5 \\
\hline
\end{tabular}

Note: Conversion ratios with oral morphine. The conversion ratio is flexible and dependent on indications for opioid switching.

Table 3 Morphine:fentanyl

\begin{tabular}{lll}
\hline $\begin{array}{l}\text { IV/SC } \text { morphine } \\
(\mathbf{m g})\end{array}$ & $\begin{array}{l}\text { Oral morphine } \\
(\mathbf{m g})\end{array}$ & $\begin{array}{l}\text { TTS fentanyl } \\
(\boldsymbol{\mu g} / \mathbf{h})\end{array}$ \\
\hline 20 & 60 & 25 \\
40 & 120 & 50 \\
60 & 180 & 75 \\
80 & 240 & 100 \\
\hline
\end{tabular}

Note: Switching from oral morphine to TTS fentanyl: practical advice and information. Equivalency ratio 100:I (oral morphine mg/24 h; TTS fentanyl mg/24 h). Abbreviations: IV, intravenous; SC, subcutaneous; TTS, time to switch.

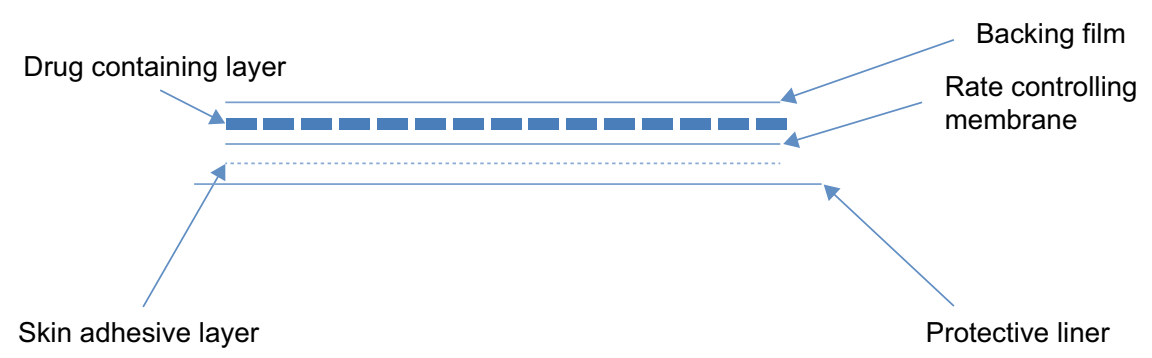

Figure 4 Schematic representation of the matrix form of fentanyl. 
Table 4 Rotation to fentanyl algorithm

\begin{tabular}{|c|c|}
\hline Step I & Calculate the total daily dose of the current opioid \\
\hline Step 2 & $\begin{array}{l}\text { Calculate the equinalgesic 24-hour morphine parenteral } \\
\text { dose }\end{array}$ \\
\hline Step 3 & Determine the equivalent transdermal fentanyl dose \\
\hline Step 4 & Continue the previous opioid for $8-12$ hours \\
\hline Step 5 & $\begin{array}{l}\text { Order adequate breakthrough dosing based on the } \\
\text { calculated total }\end{array}$ \\
\hline Step 6 & Change the fentanyl patch every 72 hours \\
\hline \multicolumn{2}{|c|}{ Discontinuing TTS fentanyl } \\
\hline Step I & Calculate the equivalent dose of the new opioid \\
\hline Step 2 & $\begin{array}{l}\text { Calculate the scheduled interval and breakthrough dose of } \\
\text { the new opioid }\end{array}$ \\
\hline Step 3 & Remove the patch and start the new opioid 12 hours later \\
\hline Step 4 & $\begin{array}{l}\text { Order adequate breakthrough dosing to cover the patient } \\
\text { in the interval }\end{array}$ \\
\hline
\end{tabular}

Notes: Switching from another opioid to transdermal fentanyl (TTS fentanyl) or discontinuing transdermal fentanyl - a practical guide. Changing from another opioid to TTS fentanyl.

Abbreviation: TTS, time to switch.

Hanaoka et al evaluated 66 cancer patients for the efficacy and safety of the 24-hour-release fentanyl patch, as a rotation from other opioids. The preceding treatment was maintained concomitantly for another 2 days. Evaluation after 10 days showed analgesia efficiency in $57.6 \%$ of patients, without major adverse effects. The 24-hour administration form has the same efficiency as the one for 72 hours. ${ }^{50}$

Regarding survival after performing an opioid rotation, a study conducted by Reddy et al showed that patients with advanced disease, with a reduced performance status, and opioid-induced neurotoxicity with a high Memorial Delirium Assessment Scale score had a reduced survival. These patients require careful monitoring, especially after the rotation. ${ }^{51}$ Furthermore, patients who had inefficient analgesia following rotation also had a reduced survival. ${ }^{52}$

\section{Conclusion}

Pain management in clinical practice has benefited - during recent years - from clear and efficient guidelines, and also due to the advent of new drugs. Current therapeutic modalities offer multiple options for cancer patients so that pain can be efficiently controlled and palliation is feasible. Opioid rotation can achieve a favorable analgesia/toxicity ratio. Fentanyl therapy allows an improvement in life quality through good analgetic control, and a reduction of adverse effects, including digestive symptoms, the quality of sleep and awakening vigilance, as well as avoiding injectable and oral administrations.

Fentanyl induces far fewer adverse neurologic effects, is efficient and - most importantly - is safe, even if the patch is changed at 4 hours. Eligible patients are those in whom the pain is controlled at stable medium or small doses of opioid, patients with nausea or vomiting after other opioids and patients in which oral administration is difficult because of dysphagia or because of eso-gastric localization of the tumor. The initial dose of fentanyl treatment has to be reduced by $25 \%-50 \%$ compared to equivalent doses of oral morphine and the anterior opioid has to be maintained for a further 8-12 hours so the action of fentanyl can take place; the dose ratio of conversion of morphine:fentanyl can vary between 70 and 150:1.

Sweating, however, remains a problem and can make fentanyl administration difficult, but this can be overcome by using a fentanyl matrix. Fentanyl therapy is recommended to be continued during chemotherapy, radiotherapy, or in the case of surgical interventions. Rotation to fentanyl patches is an efficient and elegant solution with reduced adverse effects for cancer patients.

Opioid rotation, especially to fentanyl, has been shown to cause an overall increase in the quality of life in patients with malignant disease. Finally, rotation to fentanyl is also advantageous from an economic point of view.

\section{Acknowledgments}

This work was supported by grants from the Romanian National Authority for Scientific Research and Innovation, CNCS - UEFISCDI, project number PNII-RU-TE-2014-4-2074 (to M Zdrenghea) and PN-II-RUTE-2014-4-1783 (to C Tomuleasa), a Romania-Norway grant awarded to C Tomuleasa and I Berindan-Neagoe (F-SEE-027, 1/25.06.2015), and a doctoral grant awarded to I Frinc by the Iuliu Hatieganu University of Medicine and Pharmacy

\section{Disclosure}

The authors report no conflicts of interest in this work.

\section{References}

1. Smith HS, Peppin JF. Toward a systematic approach to opioid rotation. J Pain Res. 2014;7:589-608.

2. Sarzi-Puttini P, Vellucci R, Zuccaro SM, Cherubino P, Labianca R, Fornasari D. The appropriate treatment of chronic pain. Clin Drug Invest. 2012;32(Suppl 1):21-33.

3. Kim HJ, Kim YS, Park SH. Opioid rotation versus combination for cancer patients with chronic uncontrolled pain: a randomized study. BMC Palliat Care. 2015;14:41.

4. Ferrell B, Levy MH, Paice J. Managing pain from advanced cancer in the palliative care setting. Clin J Oncol Nurs. 2008;12(4):575-581.

5. King S, Forbes K, Hanks GW, Ferro CJ, Chambers EJ. A systematic review of the use of opioid medication for those with moderate to severe cancer pain and renal impairment: a European Palliative Care Research Collaborative opioid guidelines project. Palliat Med. 2011;25(5): 525-552.

6. Anderson R, Saiers JH, Abram S, Schlicht C. Accuracy in equianalgetic dosing. conversion dilemmas. J Pain Symptom Manage. 2001;21(5): 397-406. 
7. Gatti A, Reale C, Luzi M, et al. Effects of opioid rotation in chronic pain patients: ORTIBARN study. Clin Drug Invest. 2010;30(Suppl 2):39-47.

8. Korte W, de Stoutz N, Morant R. Day-to-day titration to initiate transdermal fentanyl in patients with cancer pain: short- and long-term experiences in a prospective study of 39 patients. J Pain Symptom Manage. 1996;11(3):139-146.

9. Mercadante S. Opioid rotation for cancer pain: rationale and clinical aspects. Cancer. 1999;86(9):1856-1866.

10. Indelicato RA, Portenoy RK. Opioid rotation in the management of refractory cancer pain. J Clin Oncol. 2002;20(1):348-352.

11. Knotkova H, Fine PG, Portenoy RK. Opioid rotation: the science and the limitations of the equianalgetic dose table. J Pain Symptom Manage. 2009;38(3):426-439.

12. Samolsky Dekel BG, Tomasi M, Vasarri A, et al. Opioid titration with sustained-release oxycodone and immediate-release morphine for moderate/severe cancer pain: a pilot assessment of the CoDem protocol. J Opioid Manag. 2014;10(1):29-38.

13. Mercadante S, Bruera E. Opioid switching in cancer pain: from the beginning to nowadays. Crit Rev Oncol Hematol. 2016;99: 241-248.

14. Nalamachu SR. Opioid rotation in clinical practice. Adv Ther. 2012; 29(10):849-863.

15. Mercadante S, Valle A, Porzio G, et al. Opioid switching in patients with advanced cancer followed at home. A retrospective analysis. J Pain Symptom Manage. 2013;45(2):298-304.

16. Niv D, Nemirovsky A, Rudick V, Geller E, Urca G. Antinociception induced by simultaneous intrathecal and intraperitoneal administration of low doses of morphine. Anesth Analg. 1995;80(5):886-889.

17. Hayashi T, Ikehata S, Matsuzaki H, et al. Influence of serum albumin levels during opioid rotation from morphine or oxycodone to fentanyl for cancer pain. Biol Pharm Bull. 2014;37(12):1860-1865.

18. Ericson L, Ambring A, Bjorholt I, Dahm P. Opioid rotation in patients initiated on oxycodone or morphine: a register study. J Pain Res. 2013;6:379-386.

19. Didwaniya N, Reddy A, Gottumukkala RS, Bruera E. What is your gut feeling about opioid rotation? J Clin Oncol. 2015;33(3):e11-e12.

20. Riley J, Ross JR, Rutter D, et al. No pain relief from morphine? Individual variation in sensitivity to morphine and the need to switch to an alternative opioid in cancer patients. Support Care Cancer. 2006;14(1):56-64.

21. Kawano C, Hirayama T, Kuroyama M. Dose conversion in opioid rotation from continuous intravenous infusion of morphine hydrochloride injection to fentanyl patch in the management of cancer pain. Yakugaku Zasshi. 2011;131(3):463-467.

22. Tawfik MO, Bryuzgin V, Kourteva G, Group F-I-S. Use of transdermal fentanyl without prior opioid stabilization in patients with cancer pain. Curr Med Res Opin. 2004;20(3):259-267.

23. Schug SA, Chandrasena C. Pain management of the cancer patient. Exp Opin Pharmacother. 2015;16(1):5-15.

24. Qaseem A, Snow V, Shekelle P, et al. Evidence-based interventions to improve the palliative care of pain, dyspnea, and depression at the end of life: a clinical practice guideline from the American College of Physicians. Ann Intern Med. 2008;148(2):141-146.

25. Vadalouca A, Moka E, Argyra E, Sikioti P, Siafaka I. Opioid rotation in patients with cancer: a review of the current literature. J Opioid Manag. 2008;4(4):213-250.

26. Afsharimani B, Kindl K, Good P, Hardy J. Pharmacological options for the management of refractory cancer pain-what is the evidence? Support Care Cancer. 2015;23(5):1473-1481.

27. Pasternak GW. Preclinical pharmacology and opioid combinations. Pain Med. 2012;13(Suppl 1):S4S11.

28. Mercadante S, Caraceni A. Conversion ratios for opioid switching in the treatment of cancer pain: a systematic review. Palliat Med. 2011; 25(5):504-515.
29. Bruera E, Paice JA. Cancer pain management: safe and effective use of opioids. Am Soc Clin Oncol Educ Book. 2015:e593-e599.

30. Sato M, Miyamori T, Koyanagi J, et al. [2 cases of successful symptom management at home by using opioid rotation from a fentanyl preparation to a continuous subcutaneous injection of morphine hydrochloride, at a dose less than the equivalent dose based on the conversion table]. Gan To Kagaku Ryoho. 2012;39(Suppl 1):58-60. Japanese.

31. Reddy A, Yennurajalingam S, Pulivarthi K, et al. Frequency, outcome, and predictors of success within 6 weeks of an opioid rotation among outpatients with cancer receiving strong opioids. Oncologist. 2013;18(2):212-220.

32. Kaasa S. Is cancer pain control improved by a simple WHO pain analgetic ladder approach combined with tumor-directed treatment? J Clin Oncol. 2016;34(5):399-400.

33. McNicol E, Horowicz-Mehler N, Fisk RA, et al. Management of opioid side effects in cancer-related and chronic noncancer pain: a systematic review. J Pain. 2003;4(5):231-256.

34. Webster LR, Fine PG. Review and critique of opioid rotation practices and associated risks of toxicity. Pain Med. 2012;13(4): 562-570.

35. Ikeda M, Sonoo H, Kurebayashi J, et al. [A pilot study of the reduced effects of adverse events caused by oral morphine and oxycodone after rotating to fentanyl patch in patients with metastatic breast cancer]. Gan To Kagaku Ryoho. 2012;39(4):599-603. Japanese.

36. Reddy A, Tayjasanant S, Haider A, et al. The opioid rotation ratio of strong opioids to transdermal fentanyl in cancer patients. Cancer. 2016;122(1):149-156

37. Kato K, Mizaki T, Yamazaki S, et al. A study of transdermal fentanyl in cancer pain at Aichi-Cancer Center. Yakugaku Zasshi. 2004; 124(5):287-291.

38. Shaheen PE, Walsh D, Lasheen W, Davis MP, Lagman RL. Opioid equianalgetic tables: are they all equally dangerous? J Pain Symptom Manage. 2009;38(3):409-417.

39. Donner B, Zenz M, Tryba M, Strumpf M. Direct conversion from oral morphine to transdermal fentanyl: a multicenter study in patients with cancer pain. Pain. 1996;64(3):527-534.

40. Akiyama Y, Iseki M, Izawa R, et al. [Usefulness of fentanyl patch (Durotep) in cancer patients when rotated from morphine preparations]. Masui. 2007;56(3):317-323. Japanese.

41. Ripamonti C, Fagnoni E, Campa T, Brunelli C, De Conno F. Is the use of transdermal fentanyl inappropriate according to the WHO guidelines and the EAPC recommendations? A study of cancer patients in Italy. Support Care Cancer. 2006;14(5):400-407.

42. Fine PG, Portenoy RK; Ad Hoc Expert Panel on Evidence R, Guidelines for Opioid Rotation. Establishing "best practices" for opioid rotation: conclusions of an expert panel. J Pain Symptom Manage. 2009;38(3):418-425.

43. Mystakidou K, Befon S, Kouskouni E, et al. From codeine to transdermal fentanyl for cancer pain control: a safety and efficacy clinical trial. Anticancer Res. 2001;21(3C):2225-2230.

44. van Seventer R, Smit JM, Schipper RM, Wicks MA, Zuurmond WW. Comparison of TTS-fentanyl with sustained-release oral morphine in the treatment of patients not using opioids for mild-to-moderate pain. Curr Med Res Opin. 2003;19(6):457-469.

45. Radbruch L, Elsner F. Clinical experience with transdermal fentanyl for the treatment of cancer pain in Germany. Keio J Med. 2004; 53(1):23-29.

46. Elsner F, Radbruch L, Sabatowski R, Brunsch-Radbruch A, Loick G, Grond S. [Switching opioids to transdermal fentanyl in a clinical setting]. Schmerz. 1999;13(4):273-278. German.

47. Freynhagen R, von Giesen HJ, Busche P, Sabatowski R, Konrad C, Grond S. Switching from reservoir to matrix systems for the transdermal delivery of fentanyl: a prospective, multicenter pilot study in outpatients with chronic pain. J Pain Symptom Manage. 2005;30(3): 289-297. 
48. Oldenmenger WH, Lieverse PJ, Janssen PJ, Taal W, van der Rijt CC, Jager A. Efficacy of opioid rotation to continuous parenteral hydromorphone in advanced cancer patients failing on other opioids. Support Care Cancer. 2012;20(8):1639-1647.

49. Hanaoka K, Yoshimura T, Tomioka T, Sakata H. [Clinical study of one-day fentanyl patch in patients with cancer pain - evaluation of the efficacy and safety in relation to treatment switch from opioid analgetic therapy]. Masui. 2011;60(2):147-156. Japanese.

50.Roulet L, Luthy C, Garin N, et al. [Opioid rotation: from theory to practice. Interdisciplinary recommendations from the Geneva University Hospitals pain network]. Rev Med Suisse. 2011;7(301):1400-1404, 1406. French.
51. Reddy A, Yennurajalingam S, de la Cruz M, et al . Factors associated with survival after opioid rotation in cancer patients presenting to an outpatient supportive care center. J Pain Symptom Manage. 2014;48(1): 92-98.

52. Reddy A, Yennurajalingam S, Reddy S, et al. The opioid rotation ratio from transdermal fentanyl to "strong" opioids in patients with cancer pain. J Pain Symptom Manage. 2016;51(6): 1040-1045.

53. Morita T, Takigawa C, Onishi $\mathrm{H}$, et al. Opioid rotation from morphine to fentanyl in delirious cancer patients: an open-label trial. J Pain Symptom Manage. 2005;30(1):96-103.

\section{Publish your work in this journal}

The Journal of Pain Research is an international, peer reviewed, open access, online journal that welcomes laboratory and clinical findings in the fields of pain research and the prevention and management of pain. Original research, reviews, symposium reports, hypothesis formation and commentaries are all considered for publication.
Dovepress

The manuscript management system is completely online and includes a very quick and fair peer-review system, which is all easy to use. Visit http://www.dovepress.com/testimonials.php to read real quotes from published authors. 